\title{
An Argument for Clarity:
}

\section{What are Learning Management Systems, What are They Not, and What Should They Become?}

By William R. Watson and Sunnie Lee Watson

The application of computers to education has a history dating back to the 1950s, well before the pervasive spread of personal computers (Reiser, 1987). With a mature history and varying approaches to utilizing computers for education, a veritable alphabet

"A veritable alphabet soup

of terms and acronyms related

to computers have found their way into the literature." soup of terms and acronyms related to computers in education have found their way into the literature, most of them non-standardized. Learning Management System (LMS) is one approach to the application of computers to education which holds great potential and important concepts yet is often misunderstood and the term misused. This article will clarify the use of the term LMS by presenting a history and definition of LMS, differentiating it from similar terms with which it is often confused, and discussing the role it can play in education. It will then describe current application and available features of LMSs, and conclude by identifying trends and recommending future research.

\section{History and definition of LMS: What are LMSs?}

The history of the application of computers to education is filled with generic terms such as computer-based instruction (CBI), computerassisted instruction (CAI), and computerassisted learning (CAL), generally describing drill-and-practiceprograms, more sophisticated tutorials and more individualized instruction, respectively (Parr \& Fung, 2001). LMS has its history in another term, integrated learning system (ILS) which offers functionality beyond instructional content such as management and tracking, personalized instruction and integration across the system (Bailey, 1993; Becker, 1993; Brush, Armstrong, Barbrow, \& Ulintz, 1999; Szabo \& Flesher, 2002).

The term ILS was coined by Jostens Learning, and LMS was originally used to describe the management system component of the PLATO $\mathrm{K}-12$ learning system, content-free and separate from the courseware (R. Foshay, personal communication, October 24, 2006). The term LMS is currently used to describe a number of different educational computer applications, and we would argue that it is often used incorrectly. Later sections of this article will differentiate LMS from other terms with which it is often confused, but prior to describing what LMS is not; we will focus on describing what an LMS is.

The key to understanding the difference between LMS and other computer education terms is to understand the systemic nature of LMS. LMS is the framework that handles all aspects of the learning process. An LMS is the infrastructure that delivers and manages instructional content, identifies and assesses individual and organizational learning or training goals, tracks the progress towards meeting those goals, and collects and presents data for supervising the learning process of an organization as a whole (Szabo \& Flesher, 2002). An LMS delivers content but also handles course registration and administration, skills gap analysis, tracking and reporting (Gilhooly, 2001).

Bailey (1993) presents the following general characteristics of an LMS in education: 
- Instructional objectives are tied to individual lessons.

- Lessons are incorporated into the standardized curriculum.

- Courseware extends several grade levels in a consistent manner.

- A management system collects the results of student performance.

- Lessons are provided based on the individual student's learning progress.

The American Society for Training \& Development (Learning Circuits, 2005), recommends these following functional requirements for a corporate LMS:

- enable integration with the human resources system

- incorporate tools which enable the administration to:

- manage user registrations and develop user profiles

- set curricula and certification paths

- assign tutors and tutorial content

- administer budgets

- prepare schedules for learners, instructors and classrooms

- provide access to content delivery involving the medium (classroom, online), method (instructor-led, selfpaced), and learners (employees, customers)

- develop content, including authoring, maintaining and storing

- integrate content with third-party courseware

- assess learners' competency gaps and manage skills acquisition and status

- provide and support authoring of assessments

- adhere to standards such as SCORM and AICC which allow for importing content and courseware that complies with standards regardless of the authoring system

- support configuration of the LMS to function with existing systems and internal processes

- provide security such as passwords and encryption

While this list of features can be helpful in understanding what an LMS is, as a systemic application, it incorporates a great many features by providing the structure of the entire learning process within an organization. Therefore, further clarity can be achieved by contrasting it with related technologies with which it is often confused.

\section{Relating LMS to CMS, LCMS and RLO: What are LMSs not?}

As the application of computers to education is awash with acronym-driven, nonstandardized terms, it is not surprising that there is often confusion as to which term is appropriate to use. A major goal of this article is to recommend a consistent use of the term LMS in the literature. In order to do this, it is important to identify some of the ways in which we believe LMS is being inappropriately used to describe separate but related technologies.

\section{Course Management Systems}

The inappropriate use of LMS in the literature is perhaps most commonly associated with computer
"The term LMS is currently used to describe a number of different computer applications." applications which we would identify as Course Management Systems (CMS). These systems are used primarily for online or blended learning, supporting the placement of course materials online, associating students with courses, tracking student performance, storing student submissions and mediating communication between the students as well as their instructor. Some of this same functionality can be seen within LMSs as well, so it is understandable why confusion might exist. However, the systemic nature of an LMS does not limit its functionality to that of a CMS.

A CMS "provides an instructor with a set of tools and a framework that allows the relatively easy creation of online course content and the subsequent teaching and management of that course including various interactions with students taking the course" (EDUCAUSE Evolving Technologies Committee, 2003, p. 1). Examples of a CMS include Blackboard, Angel, Sakai, Oncourse and Moogle. However, Blackboard is a good example of the confusion that exists regarding these terms as it is commonly referred to in the literature as an LMS.

A Google Scholar search of the phrase "blackboard lms" returned 36 articles identifying Blackboard as an LMS, while the Blackboard company itself refers to its product as a CMS: "Blackboard's online learning application, the Blackboard Learning System, is the most widely-adopted course management system [emphasis added] among U.S. postsecond- 
ary institutions" (Blackboard Company, 2006b). While Blackboard's Learning System does not comprise their entire Academic Suite, the additional products support better management of learning objects, student portfolios, and the creation of online portals, which collectively Blackboard calls a Networked

"LMS is the framework that handles all aspects of the learning process."
Learning Environment (Blackboard Company, 2006a), does not meet the full functionality necessary to be identified as an LMS. The scope of functionalities does not encompass the entire organization, and the course-focused nature of the applications is not systemic. Therefore, while a CMS could be seen as a part of an LMS, it is certainly not equivalent to an LMS. The technologies were developed for very different reasons even if they share certain functionalities (Carliner, 2005).

\section{Learning Content Management Systems}

While also being frequently confused with each other, Learning Content Management Systems (LCMS) and LMSs can be more simply contrasted as they are very well suited to integration with each other. LCMS is often used interchangeably with LMS or touted as a newer version of LMS. In reality, the two applications focus on different functions and complement each other well. The key difference between the two technologies is as simple as the one word separating them: content. Oakes (2002) reports that the IDC defines an LCMS as a system used to "create, store, assemble and deliver personalized e-learning content in the form of learning objects" (p. 73). The focus with LCMS is content as "it tackles the challenges of creating, reusing, managing, and delivering content" (Oakes, 2002, p. 74). An LMS, however, is "learner and organization focused: It's concerned with the logistics of managing learners, learning activities and the competency mapping of an organization" (Oakes, 2002, p. 74).

LCMS and LMS certainly have a different focus but integrate very well; the LCMS allows for the creation and delivery of learning objects (LO) while LMS manages the learning process as a whole, incorporating the LCMS within it (Greenberg, 2002). Or as Connolly (2001) puts it, "LMS provides the rules and the LCMS provides the content" (p. 58).

\section{Learning objects and integrating these related technologies}

Having described the complementary nature of LCMSs and LMS as well as the different focus of CMS and LMS, and understanding the systemic nature of LMS as providing the structure within which CMS and LCMS can function, we will now examine an important technology, learning objects, which is not typically confused with LMS but which is inherently important to the integration of these related technologies. A LO represents the smallest component of content within an LCMS or LMS. LOs offer powerful potential due to their promise of reusability across multiple contexts, generativity (integrating LOs to generate new instruction), adaptability to meet the needs of individual learners and scalability to meet the needs of both larger and smaller audiences without significant changes in cost (Gibbons, Nelson, \& Richards, 2002; Hodgins, 2002; Wiley, 2002).

Essentially, a learning object can be defined as any digital media that can be reused to support learning (Watson, Lee, \& Reigeluth, 2007). It is the reusable nature of the $\mathrm{LO}$ which holds the most promise and challenges for success. In order to maximize LOs reusability, it must adhere to standards, such as SCORM or LOM, which utilize metadata to describe the object as well as the context for its use. Unfortunately, there are multiple standards for describing LOs in use as well as multiple standards "for evaluating interoperability between LMSs and content" (Connolly, 2001, p. 57).

The lack of agreement and adherence to standards with both the creation of LOs and their inclusion in LMSs results in a negative impact on reusability, flexibility and functionality. Ideally, LOs, CMS, and LCMS would be integrated together within the LMS which would act as the infrastructure to seamlessly bring together these complementary technologies. LOs would act as the smallest form of content handled by the LMS, created and delivered within an LCMS according to each individual learner's need based on current assessments and performance toward customized learning goals. The CMS would function as a course environment, organizing instructional content into discrete courses and supporting communication between learners and instructors.

\section{Role of LMS in education: What should LMSs become?}

The importance of understanding LMS as well as its related technologies lies in the role it 
will play in future approaches to instruction as the needs of today's learners are not being met by current approaches. Society has shifted from the Industrial Age into what many are calling the Information Age (Reigeluth, 1994; Senge, Cambron-McCade, Lucas, Smith, Dutton, \& Kleiner, 2000; Toffler, 1984). Today's education system remains mired in the Industrial Age, putting the onus for learning on teachers, encouraging students to remain passive, and treating all students as if they are the same and forcing them to do the same things in the same amount of time (Reigeluth, 1994). This forces achievement to vary among the students, leaving the low-achieving students behind and holding the higher-achieving students back (Reigeluth, 1997). The alternative to holding time constant and forcing learning to occur at a single rate is to hold achievement at a constant mastery level. This requires education to shift to an entirely new paradigm, from one with a focus on standardization and sorting with a high rate of failure to one that supports customization to meet all learners' needs.

In an Information Age-appropriate paradigm of education, students will be allowed as much time as they need to achieve mastery and move on immediately upon demonstrating that mastery, requiring a customized pace and sequencing of instruction (Schlechty, 1991). Instruction will move to a more learner-centered approach as teachers cease acting primarily as knowledge sources and instead become facilitators of the knowledge acquisition process by acting as guides, coaches, and motivators as students become more active in their learning process (McCombs \& Whisler, 1997).

In order for the learner process to be customized for each individual learner, technology will need to play a key role. Schlechty (1991) argues that technology will be needed to track each student's progress towards mastery, assess their learning, help teachers understand what sort of guidance is needed, provide and appropriately sequence instruction, store evidence of attainments and systemically integrate each of these functions. It is clear that this description is closely aligned to the functions of an LMS.

In an Information Age model of education, an LMS will assess learners' current knowledge and skill level, work with teachers and learners to identify appropriate learning goals, identify and sequence instruction appropriate for the individual learner, assess learner performance products, store evidence of attainments, support collaboration and generate reports to provide information to maximize the effectiveness of the entire learning organization. While LMSs can currently perform some of these functions, limitations exist which are hindering the full realization of LMSs' potential.

We have previously discussed the challenges presented by lack of agreement and adherence regarding standards that result in a negative impact on the reusability of learning objects and the effectiveness and efficiency of LMSs. LOs are difficult enough to create but the challenge of then applying standards which will result in easy implementation within an LCMS or LMS are an additional headache for instructional designers.

Without effective use of standards, even an LO well suited to broad reuse is unlikely to be reused due to the lack of awareness regarding its availability. Some work is currently being done on Automatic Metadata Generation (AMG) in order to ease the load on designers to have to tie their instruction to standards themselves ( $\mathrm{Au}$ tomatic Metadata Generation, 2006).

The challenges of creating effective LOs needs to be addressed with better authoring tools allowing for the creation of effective instruction suitable for specific types of learners. Many of the current K-12 LMS platforms utilize older instruction which has been minimally updated if at all. The reason is the immense cost in developing the instruction, estimated as high as $\$ 100$ million to build a comparative system today (R. Foshay, personal communication, October 24, 2006). By incorporating authoring tools to allow for easier creation of learning objects by practitioners, some of these challenges can be overcome.

The increasing availability of open-source technologies is another potential advantage, dispersing the resource load for creating, updating, and maintaining these technologies across a global community of developers rather than one or two private companies. Ultimately, LMSs need to

- provide more constructivist-based instruction, focusing on flexible, learner-defined goals (Reigeluth \& Garfinkle, 1994)

- support collaborative learning inside and outside of the school in order to extend the learning environment to the home and further involve parents (Taylor, 2004)

- better address personalized assessment, progress tracking, reporting, and responsiveness to learner needs (Reigeluth \& Garfinkle, 1994) 
- truly become systemic, integrating systems seamlessly to allow for improved collaboration across systems and among stakeholders (Sherry, 1992)

- improve support for professional diagnosis and development for stakeholders, including teachers

- improve cost effectiveness and better leverage existing resources currently available in schools and LMSs (Szabo \& Flesher, 2002)

While serious challenges are currently impeding LMSs from realizing their full potential, perhaps the greatest possibility for improving these technologies lies in the hands of learners, teachers, and other stakeholders in the current educational system. That is, once they demand a shift to an Information Age paradigm of instruction, the full and centralized implementation of LMSs will be necessary, and the attention to maximizing their potential will naturally be realized.

\section{Overview of major LMS: What do current LMSs offer?}

This final section will present an overview of the status of several major LMSs available today. LMSs are more typically utilized in corporate settings with many available systems on the market, including NetDimensions EKP, Saba and SumTotal Systems (Carliner, 2005),

"Perhaps the greatest possibility for improving these technologies lies in the hands of learners, teachers, and other stakeholders." as well as Lotus, Oracle iLearning and Cornerstone OnDemand, among others (Learning Circuits, 2005). A 2006 survey highlights the features most commonly found in the corporate LMSs currently being utilized (2006 Survey of Learning Management Systems, 2006).

In the K-12 market, two major systems have been absorbing the smaller products over the last several years. The following table reflects a summary of the previous research we have conducted in which we generated a conceptual framework of major features in order to evaluate and compare the major K-12 LMSs (Watson, Lee, \& Reigeluth, 2007). We reviewed corporate literature to identify which features each LMS offered, and with the exception of PLATO, whose representatives declined comment, had each company review and approve our conclusions. It should be stated that while the table represents our conclusions, the LMSs are composed of multiple products, and it is unclear how well these products function together, so it is possible that not all features listed will function together as a complete package. Furthermore, some of the features are more of a matter of degree rather than a simple yes or no.

We have updated the table as Pearson Digital Learning recently purchased Co-nect, and we made a small change in wording regarding the direct instruction feature to better reflect our original intentions of the meaning of the word in the LMS context. Within the list of features, the table shades features that are important for instruction within the Information Age paradigm.

\section{Conclusion}

LMSs are a powerful technology that have yet to reach their full potential and are important for the Information Age paradigm of education. Because of their importance, greater care and understanding needs to be used when applying the term in research literature. By coming to an understanding of what LMSs are and how complementary technologies can be integrated with an LMS, researchers and practitioners will better be able to communicate regarding the
"We will need to conduct research to help guide decisions and future
applications
of technology." state and future of computers in education. However, understanding and consistent use of terms alone is not sufficient for the potential of computer technologies in education to be realized. There is a real dearth of solid research on LMSs.

Studies about the implementation and effectiveness of the LMS products discussed in this article are needed. These studies should examine more closely what features these products offer and identify the additional features that are needed. Student, teacher, parent and other stakeholder perceptions of these products as well as the individual features should be described. Furthermore, more research is needed in the area of learning object authoring and adherence to standards.

With the constant adoption and discarding of terms in the fast-paced world of computers, communication can be hindered, concepts blurred and research stunted. It is important to keep an eye on the needs of today's learners and 


\begin{tabular}{|c|c|c|c|c|c|}
\hline \multicolumn{3}{|c|}{$\begin{array}{l}\text { Features } \\
\text { (grayed features support information-age needs) }\end{array}$} & PLATO & $\begin{array}{l}\text { Pearson } \\
\text { Digital } \\
\text { Learning }\end{array}$ & $\begin{array}{l}\text { Achievement } \\
\text { Technologies }\end{array}$ \\
\hline \multirow{19}{*}{$\begin{array}{l}\text { Instructional } \\
\text { Method }\end{array}$} & \multirow{9}{*}{$\begin{array}{l}\text { Standard } \\
\text { features }\end{array}$} & Content presentation & $\sqrt{ }$ & $\sqrt{ }$ & $\sqrt{ }$ \\
\hline & & Curriculum standards & $\sqrt{ }$ & $\sqrt{ }$ & $\sqrt{ }$ \\
\hline & & $\begin{array}{l}\text { Supporting teacher-directed } \\
\text { instruction }\end{array}$ & & $\sqrt{ }$ & \\
\hline & & Bilingual & $\sqrt{ }$ & $\sqrt{ }$ & $\sqrt{ }$ \\
\hline & & Self-paced learning & $\sqrt{ }$ & $\sqrt{ }$ & $\sqrt{ }$ \\
\hline & & Project-based work & & $\sqrt{ }$ & \\
\hline & & Group work & & & $\sqrt{ }$ \\
\hline & & Authentic, real-world problems & & $\sqrt{ }$ & $\sqrt{ }$ \\
\hline & & Individualized instruction & $\sqrt{ }$ & $\sqrt{ }$ & $\sqrt{ }$ \\
\hline & \multirow{4}{*}{$\begin{array}{l}\text { Teacher } \\
\text { customiz- } \\
\text { ability }\end{array}$} & Adaptive sequencing & $\sqrt{ }$ & $\sqrt{ }$ & $\sqrt{ }$ \\
\hline & & Adaptive lesson plans & & $\sqrt{ }$ & $\sqrt{ }$ \\
\hline & & $\begin{array}{l}\text { Customizable instructional } \\
\text { content }\end{array}$ & & $\sqrt{ }$ & $\sqrt{ }$ \\
\hline & & Prescription of lessons & $\sqrt{ }$ & $\sqrt{ }$ & $\sqrt{ }$ \\
\hline & \multirow{6}{*}{$\begin{array}{l}\text { Outside } \\
\text { school }\end{array}$} & Online message center & & $\sqrt{ }$ & \\
\hline & & Online discussion board & & $\sqrt{ }$ & \\
\hline & & Project-based work & & $\sqrt{ }$ & \\
\hline & & $\begin{array}{l}\text { Activities/homework with } \\
\text { parent involvement }\end{array}$ & $\sqrt{ }$ & $\sqrt{ }$ & $\sqrt{ }$ \\
\hline & & $\begin{array}{l}\text { Community relations and } \\
\text { support }\end{array}$ & $\sqrt{ }$ & $\sqrt{ }$ & \\
\hline & & $\begin{array}{l}\text { Online lesson plan } \\
\text { management for teachers }\end{array}$ & & $\sqrt{ }$ & \\
\hline \multirow{7}{*}{\multicolumn{2}{|c|}{ Data management }} & Attendance & & $\sqrt{ }$ & \\
\hline & & Health information & & $\sqrt{ }$ & \\
\hline & & Parent/guardian information & & $\sqrt{ }$ & \\
\hline & & Enrollment & & $\sqrt{ }$ & \\
\hline & & Class schedule & & $\sqrt{ }$ & \\
\hline & & $\begin{array}{l}\text { Record of attainments } \\
\text { mastered }\end{array}$ & $\sqrt{ }$ & $\sqrt{ }$ & $\sqrt{ }$ \\
\hline & & Mastery progress & $\sqrt{ }$ & $\sqrt{ }$ & $\sqrt{ }$ \\
\hline \multirow{5}{*}{\multicolumn{2}{|c|}{ Assessment }} & Post test / Pre test & $\sqrt{ }$ & $\sqrt{ }$ & $\sqrt{ }$ \\
\hline & & Formative tests & & $\sqrt{ }$ & \\
\hline & & Practice tests & $\sqrt{ }$ & $\sqrt{ }$ & \\
\hline & & Diagnostic tests & $\sqrt{ }$ & $\sqrt{ }$ & $\sqrt{ }$ \\
\hline & & Mastery-level tests & $\sqrt{ }$ & $\sqrt{ }$ & $\sqrt{ }$ \\
\hline \multirow{6}{*}{ Reporting } & & $\begin{array}{l}\text { Summative test report to } \\
\text { teachers/ parents }\end{array}$ & $\sqrt{ }$ & $\sqrt{ }$ & $\sqrt{ }$ \\
\hline & & $\begin{array}{l}\text { Formative test report to } \\
\text { teachers/parents }\end{array}$ & $\sqrt{ }$ & $\sqrt{ }$ & $\sqrt{ }$ \\
\hline & & $\begin{array}{l}\text { Student information report to } \\
\text { teachers/ parents }\end{array}$ & & $\sqrt{ }$ & \\
\hline & & $\begin{array}{l}\text { Record of attainments report to } \\
\text { teachers/ parents }\end{array}$ & $\sqrt{ }$ & $\sqrt{ }$ & $\sqrt{ }$ \\
\hline & & $\begin{array}{l}\text { Mastery progress report to } \\
\text { teachers/ parents }\end{array}$ & $\sqrt{ }$ & $\sqrt{ }$ & $\sqrt{ }$ \\
\hline & & $\begin{array}{l}\text { Customizable reporting for } \\
\text { teachers }\end{array}$ & & $\sqrt{ }$ & \\
\hline
\end{tabular}

Table 1: Comparison of major features of K-12 LMS products 
how technology can be maximized to best meet those needs and to conduct research to help guide decisions and future applications of technology.

William R. Watson is a lecturer in Computer and Information Technology, Purdue School of Engineering Technology, Indiana University - Purdue University Indianapolis and a doctoral student in the Instructional Systems Technology Department at Indiana University, Bloomington. His research interest focuses on advanced technologies for Information Age instruction, including the design of instructional video games and Learning Management Systems. He may be reached atwwatson@iupui. edu.

Sunnie Lee Watson is an associate instructor and doctoral student in the Instructional Systems Technology Department at Indiana University, Bloomington. Her research focus lies in the learner-centered paradigm of instruction, technology integration in K-12 classrooms, and systemic change in education. She may be reached atsuklee@indiana.edu.

\section{References}

Automatic Metadata Generation. (2006). Introduction: Why we need AMG, first version, and redesign. Retrieved November 20, 2006, from http://ariadne. cs.kuleuven.be/amg/Intro.jsp

Bailey, G. D. (1993). Wanted: A road map for understanding Integrated Learning Systems. In G. D. Bailey (Ed.), Computerbased Integrated Learning Systems (pp. 3-9). Englewood Cliffs, NJ: Educational Technology Publications.

Becker, H. J. (1993). A model for improving the performance of Integrated Learning Systems. In G. D. Bailey (Ed.), Computerbased Integrated Learning Systems (pp. 11-31). Englewood Cliffs, NJ: Educational Technology Publications.

Blackboard Company. (2006a). Blackboard Academic Suite brochure. Retrieved November 14, 2006, from http://library. blackboard.com/docs/as/bb_academic_ suite_brochure_single.pdf

Blackboard Company. (2006b). Evaluating education. Retrieved November 21, 2006, from http://www.blackboard.com/ company/

Brush, T. A., Armstrong, J., Barbrow, D., \& Ulintz, L. (1999). Design and delivery of Integrated Learning Systems: Their impact on students achievement and attitudes.
Educational Computing Research, 21(4), 475-486.

Carliner, S. (2005). Course management systems versus learning management systems. Learning Circuits. Retrieved November 20, 2006, from http://www.learningcircuits.org/2005/nov2005/carliner. htm

Connolly, P. J. (2001). A standard for success. InfoWorld, 23(42), 57-58.

EDUCAUSE Evolving Technologies Committee. (2003). Course Management Systems (CMS). Retrieved November 20, 2006, from http://www.educause.edu/ir/library/ pdf/DEC0302.pdf

Gibbons, A. S., Nelson, J. M., \& Richards, R. (2002). The nature and origin of instructional objects. In D. A. Wiley (Ed.), The instructional use of learning objects: Online version. Retrieved November 20, 2006, from http://reusability.org/read/chapters/ gibbons.doc

Gilhooly, K. (2001). Making e-learning effective. Computerworld, 35(29), 52-53.

Greenberg, L. (2002). LMS and LCMS: What's the Difference?. Retrieved November 20, 2006, from http://www.learningcircuits. org/2002/dec2002/greenberg.htm.

Hodgins, H. W. (2002). The future of learning objects. In D. A. Wiley (Ed.), The instructional use of learning objects: Online version. Retrieved November 20, 2006, from http://reusability.org/read/chapters/ hodgins.doc

Learning Circuits. (2005). A field guide to learning management systems. Retrieved November 12, 2006, from http:// www.learningcircuits.org/NR/rdonlyres/BFEC9F41-66C2-42EF-BE9DE4FA0D3CE1CE/7304/LMS_fieldguide1. pdf

Learning Circuits. (2006). 2006 Survey of Learning management systems. Retrieved November 20, 2006, from http:// www.learningcircuits.org/2006/August/ 2006LMSresults.htm

McCombs, B., \& Whisler, J. (1997). The learnercentered classroom and school. San Francisco: Jossey-Bass.

Oakes, K. (2002). E-learning: LCMS, LMSThey're not just acronyms but powerful systems for learning. Training \& Development, 56(3), 73-75.

Parr, J. M., \& Fung, I. (2006). A review of the literature on computer-assisted learning, particularly Integrated Learning Systems, and outcomes with respect to literacy and numeracy. Retrieved November 20, 2006, from http://www.minedu.govt.nz/index. $\mathrm{cfm}$ ?layout $=$ document $\&$ documentid $=5$ 499\&indexid=6920\&indexparentid=1024
Reigeluth, C. M. (1994). The imperative for systemic change. In C. M. Reigeluth \& R. J. Garfinkle (Eds.), Systemic change in education (pp. 3-11). Englewood Cliffs, NJ: Educational Technology Publications.

Reigeluth, C. M. (1997). Educational standards: To standardize or to customize learning? Phi Delta Kappan, 79(3), 202-206.

Reigeluth, C. M., \& Garfinkle, R. J. (1994). Envisioning a new system of education. In C. M. Reigeluth \& R. J. Garfinkle (Eds.), Systemic change in education (pp. 59-70). Englewood Cliffs, NJ: Educational Technology Publications.

Reiser, R. A. (1987). Instructional technology: A history. In R. M. Gagne (Ed.), Instructional technology: Foundations (pp. 11-48). Hillsdale, NJ: Lawrence Erlbaum Associates.

Schlechty, P. C. (1991). Schools for the 21st century: Leadership imperatives for educational reform. San Francisco: Jossey-Bass Inc.

Senge, P., Cambron-McCabe, N., Lucas, T., Smith, B., Dutton, J., \& Kleiner, A. (2000). Schools that learn: A fifth discipline fieldbook for educators, parents, and everyone who cares about education. Toronto, Canada: Currency.

Sherry, M. (1992). Integrated learning systems: What may we expect in the future? Educational Technology, 32(9), 58-59.

Szabo, M., \& Flesher, K. (2002). CMI theory and practice: Historical roots of learning management systems. Paper presented at the E-Learn 2002 World Conference on E-Learning in Corporate, Government, Healthcare, \& Higher Education, Montreal, Canada.

Taylor, F. P. (2004). Education technology helps unite school communities, improve academic achievement. T.H.E. Journal, 31(10), 46-48.

Toffler, A. (1984). The third wave. New York: Bantam.

Watson, W. R., Lee, S., \& Reigeluth, C. M. (2007). Learning management systems: An overview and roadmap of the systemic application of computers to education. In F. M. M. Neto \& F. V. Brasileiro (Eds.), Advances in computer-supported learning (pp. 66-96). London: Information Science Publishing.

Wiley, D. (2002). Connecting learning objects to instructional design theory: A definition, a metaphor, and a taxonomy. In D. A. Wiley (Ed.), The instructional use of learning objects: Online version. Retrieved November 20, 2006, from http://reusability.org/read/chapters/wiley.doc 